\begin{tabular}{cc|c}
\hline Tar. Bil. Der. & Journal of Agricultural Sciences \\
& $\begin{array}{c}\text { Dergi web sayfası: } \\
\text { www.agri.ankara.edu.tr/dergi }\end{array}$ & Journal homepage: \\
& www.agri.ankara.edu.tr/journal
\end{tabular}

\title{
Agrometshell Modeli ile Buğdayda Geleceğe Dönük Senaryolar ve Risk Analizi
}

\author{
Osman ŞİMŞEK ${ }^{\mathrm{a}}$, Belgin ÇAKMAK ${ }^{\mathrm{a}}$ \\ a Ankara Üniversitesi, Ziraat Fakültesi, Tarımsal Yapılar ve Sulama Bölümü, Ankara, TÜRKIYE
}

\section{ESER BILGIISİ}

Araştırma Makalesi - Bitkisel Üretim ～DOI: 10.1501/Tarimbil_0000001207

Sorumlu Yazar: Belgin ÇAKMAK, E-posta: bcakmak@ankara.edu.tr, Tel: +90(312) 5961224

Geliş Tarihi: 6 Temmuz 2012, Düzeltmelerin Gelişi: 18 Eylül 2012, Kabul: 10 Ocak 2013

\begin{abstract}
ÖZET
Yaşadığımız yüzyılda meydana gelmesi beklenen iklim değişikliği ve kuraklık, gıda güvenliğini tehdit etmektedir. Bu çalışmanın amac1, iklim değişikliğinin Türkiye'de buğday üretimini nasıl etkileyeceğinin AgroMetShell (AMS) modeli ile tahmin edilmesidir. AMS modeli kullanılarak üretilen Su Yeterlilik İndeksi (WSI) değerleri ile geleceğe dönük senaryolar ve hassasiyet analizi yapılarak buğday veriminde meydana gelmesi muhtemel düşüşler incelenmiştir. Ayrıca Birleşmiş Milletler Gıda ve Tarım Örgütü (FAO) tarafından geliştirilen AMS modelinin Türkiye'de verim analiz ve tahminleri için kullanılma olanakları araştırılmıştır. Yapılan bütün tahminlerde verimde düşüş meydana geldiği görülmüştür. En fazla düşüş \% 18.2'lik azalma ile sıcaklığın $2{ }^{\circ} \mathrm{C}$ 'lik, güneşlenme şiddetinin \% 20'lik artışı ve yağışın \% 20'lik azalışı durumunda oluşmaktadır. Tek tek değerlendirmede sıcaklık, güneşlenme şiddeti ve yağış faktörlerinde en fazla düşüş \% 6.5 ile yağışın \% 20'lik azalması durumunda ortaya çıkmaktadır. İkili değerlendirmelerde en fazla düşüş \% 13.2'lik azalma ile güneşlenme şiddetinin \% 20’lik artışı, yağışın \% 20'lik azalışı durumunda meydana gelmektedir. Anahtar Kelimeler: İklim değişikliği; Gıda güvenliği; AgroMetShell; Su yeterlilik indeksi; Verim tahmini
\end{abstract}

\section{Future-Proof Scenarios and Risk Analysis for Wheat by Agrometshell Model}

\section{ARTICLE INFO}

Research Article - Crop Production

Corresponding Author: Belgin ÇAKMAK, E-mail: bcakmak@ankara.edu.tr, Tel: +90(312) 5961224

Received: 6 July 2012, Received in Revised Form: 18 September 2012, Accepted: 10 January 2013

\begin{abstract}
Climate change to be experienced within the current century and droughts significantly threatens the food security. Objective of this study is to estimate impacts of climate change on wheat production of Turkey by using AgroMetShell (AMS) model. Possible decreases in wheat production of the country were investigated by using future-proof scenarios and risk analyses with Water Sufficiency Index (WSI) values produced by AMS model. Also the possible use of AMS model of FAO in yield analyses and estimations were also investigated in this study. Entire estimations yielded a decrease in wheat yields.
\end{abstract}


The highest decrease $(18.2 \%)$ was observed in a scenario with $2{ }^{\circ} \mathrm{C}$ decrease in temperature, $20 \%$ increase in solar radiation and $20 \%$ decrease in precipitation. Seperate evaluations of temperature, solar radiation and precipitation revealed the highest decrease (6.5\%) with $20 \%$ decrease in precipitation. Dual evaluations revealed the lowest decrease as $13.2 \%$ with $20 \%$ decrease in precipitation $20 \%$ increase in solar radiation.

Keywords: Climate change; Food security; AgroMetShell; Water sufficiency index; Yield estimation

(C) Ankara Üniversitesi Ziraat Fakültesi

\section{Giriş}

Meteorolojik faktörlerin zamansal ve mekânsal olarak büyük değişiklikler göstermesi nedeniyle tarımsal üretimde ciddi dalgalanmalar oluşmaktadır. Dünyada yaşanan iklim değişikliği ve küresel isınma sonucunda insanoğlunun gelecekle ilgili kaygıları giderek artmaktadır. 21. yüzyılın ortaları ve sonu için yapılan tahminler ve hazırlanan raporlarda sıcaklıkların önemli düzeyde

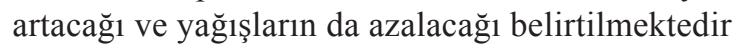
(IPCC 2007; Şimşek \& Çakmak 2010). Ayrıca nüfus artışı ile birlikte su ve gıda ihtiyacı hızla artmaktadır. Bunun sonucunda ciddi bir su ve gida güvenliği sorunu oluşması beklenmektedir. Su, gıda güvencesinin en önemli kaynağıdır. Giderek kısıtlı hale gelen su kaynaklarına olan hızlı talep artışı, tarımda kullanılan su miktarını kısıtlamakta ve dünya gida güvenliği tehlikeye girmektedir. $\mathrm{Su}$ kaynaklarında meydana gelecek azalma ve kirlenme nedeniyle içme suyu ve tarımda sulama suyu temini oldukça güçleşecektir. Özellikle Akdeniz havzasında ve yarı kurak iklim kuşağında yer alan Türkiye için yapılan tahminlerde güney ve batı bölgelerde sıcaklık artışı ve yağış azalması beklenmektedir (ÇOB 2007).

Ülkemizde 18.7 milyon hektar olan ekilebilir arazinin yaklaşık \% 83'ünde serin iklim tahılları yetiştirilmektedir. Bunun içinde buğday ve arpanın payı \% 80 civarındadır. Buğday ve arpa Anadolu'da geniş üretim alanlarına sahip temel ürünlerimizdendir. Özellikle buğday, fazla üretim seçeneklerinin bulunmadığ 1 az yağışlı bölgelerde yegâne geçim kaynağı ve insanımızın temel besin maddesi olması bakımından ekonomik ve sosyal bir değer ifade etmektedir. Yağış eksikliğinden kaynaklanan kuraklıklar tarım alanları üzerinde önemli düzeyde verim kayıplarına ve ciddi ekonomik gelir düşüşlerine neden olabilmektedir (Herdem et al 2002).

Buğdayın mevcut durumunun analizinin yapılarak gelecekte olması muhtemel verim düşüşü ve kıtlık tehlikelerine karşı önceden gerekli önlemlerin alınması bir zorunluluk haline gelmiştir. Bu kapsamda, büyük ilerleme kaydeden bilgisayar yazılımlarından faydalanarak analizler yapılmaktadır (Şimşek 2010). Şimşek et al (2007) Standart Yağış İndeksi (Standardized Precipitation Index-SPI) ve Normalin Yüzdesi İndeksi (Percent of Normal Index-PNI) yöntemlerini kullanarak Türkiye geneli için yaptıkları kuraklık analizinde, Türkiye'nin 2006-2007 Tarım Y1lı'nda son 37 yılın en kurak 5. dönemini yaşadığını belirtmişlerdir. Özellikle İç Anadolu, Ege ve Marmara Bölgeleri'nde şiddetli kuraklık yaşanmıştır. 2006-2007 Tarım Yılı yağışlarında normale göre en fazla düşüş \% 44 ile Ege'de yaşanmıştır. Düşüş oranı Marmara'da \% 33, İç Anadolu'da $\%$ 22, Akdeniz'de \% 14, Güneydoğu Anadolu'da \% 8 olmuştur. TÜİK 2007 yılı verilerine göre çok sayıda üründe ciddi kayıplar meydana geldiği belirtilmiştir. Yaşanan kuraklıktan zarar gören ürünler ve kayıp oranları; buğday $\% 13.9$, arpa $\% 23.5$, çavdar $\% 11.2$, yulaf $\% 8.4$, misır $\% 7.2$, çeltik \% 6.9, bezelye $\% 19.9$, nohut $\% 8.4$, fasulye $\%$ 21.3, mercimek \% 12.4, fiğ \% 48.4, şeker pancar1 \% 14.1, pamuk \% 10.8, ayçiçeği \% 23.6, susam $\% 24.6$, soya $\% 35.2$, zeytin $\% 39.1$, antep fıstığ1 \% 33.3, findık \% 19.8, üzüm \% 9.7, incir $\% 27.6$ şeklinde sıralanabilir.

$\mathrm{Bu}$ çalışmada, FAO tarafından geliştirilen AMS modeli kullanılarak üretilen WSI değerleri yardımıyla, Türkiye buğday üretiminin önemli 
bir kısmının yapıldığı illerde, geleceğe dönük senaryolar ve hassasiyet analizi yapılarak buğday veriminde meydana gelmesi muhtemel düşüşler incelenmiştir.

\section{Materyal ve Yöntem}

AMS modelinin kullanılabilmesi için gerekli girdiler araştırılıp temin edilmiştir. Meteorolojik veriler Devlet Meteoroloji İşleri Genel Müdürlüğünden (DMI) alınmıştır ve 260 Büyük Klima İstasyonu'na ait verileri kapsamaktadır (DMİ 2011). Veriler, günlük olarak yağış, nispi nem, rüzgar hızı, güneşlenme süresi ve şiddeti, maksimum, minimum ve ortalama hava sicaklık değerleridir. Çalışmada, güneşlenme süresi veya toplam güneş radyasyonu ölçümü yapılan 212 istasyondan buğday analizi yapılacak 10 istasyonun verileri kullanılmıştır. AMS modeli bu meteorolojik verileri kullanarak, FAO Penman-Monteith eşitliği ile referans evapotranspirasyon (ETo) değerlerini hesaplamaktadır.

Buğday için yapılan verim analiz ve tahmini çalışmasında, bu bitkiye ait bitki katsayıları mümkün olduğunca yurtiçi araştırmalardan temin edilmiş olup, eksikler FAO 56'dan alınarak tamamlanmıştır (Allen et al 1998). Modelde, her il için fenolojik gözlemler ve ilgili bitki katsayıları tanımlanmıştır. Bununla ilgili örnek bir tanımlama Şekil 1'de verilmiştir. Buğdaya ait ekim, hasat tarihleri TAGEM ve DMI''den alınmıştır. Modelde, her il için vejetasyon süresi boyunca gerçekleşen safhalar ve ilgili bitki katsayıları tanımlanmıştır. Model sulama yapıldığında bunu hesaba katabilmektedir. Ancak bu çalışmada ülke genelinde sulanmayan koşullar için model çalıştırılmıştır. Toprak su tutma kapasitesi ortalama bir değer olan 60 olarak ve etkili yağış oranı AMS kullanım kılavuzunda önerilen üst limit değeri olan 100 olarak alınmıştır (Mukhala \& Hoefsloot 2004).

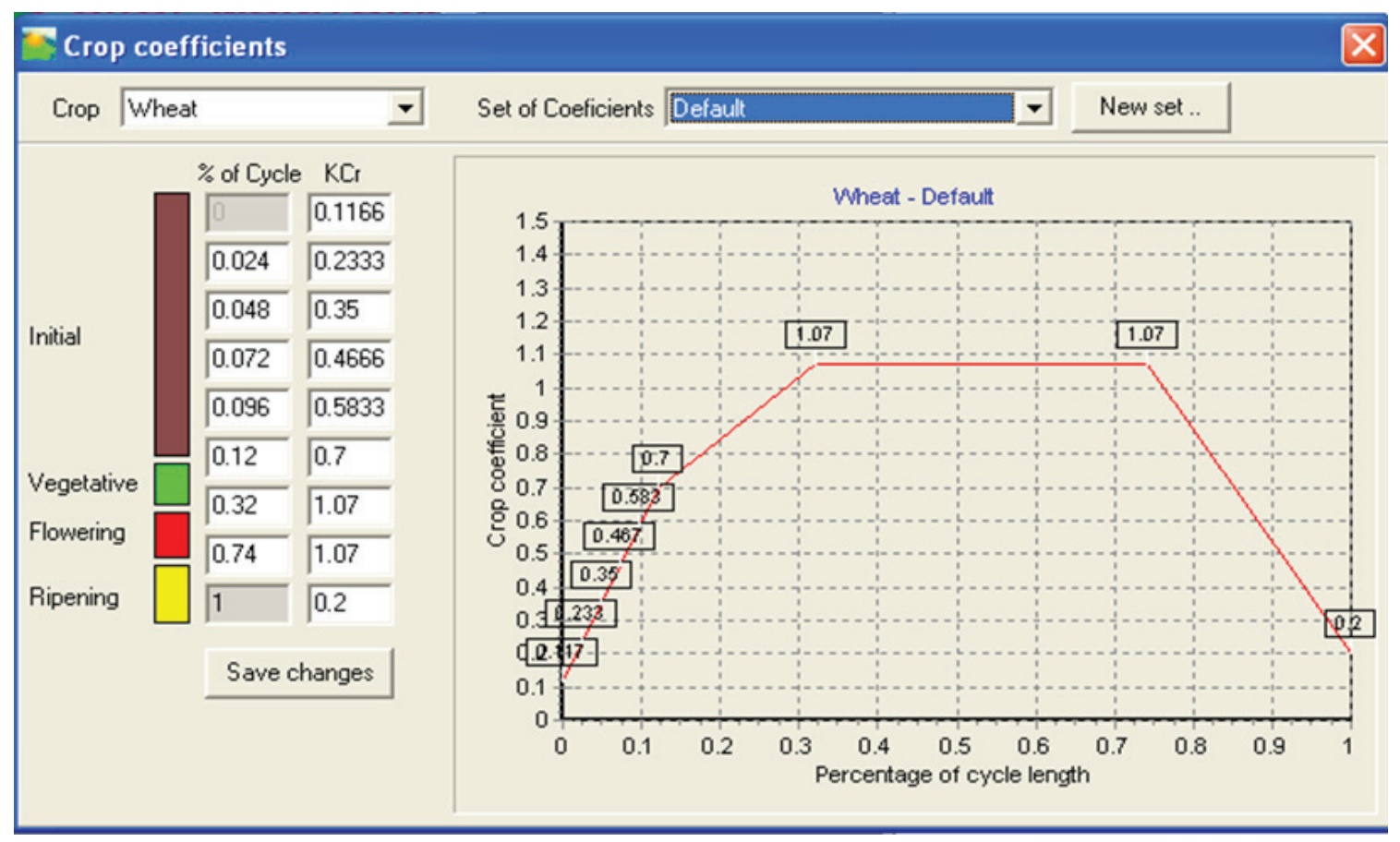

Şekil 1- Buğday için bitki katsayısının tanımlanması

Figure 1-Definition of the crop coefficient for wheat

Tarım Bilimleri Dergisi - Journal of Agricultural Sciences 18 (2012) 187-196 


\subsection{Su yeterlilik indeksi (water satisfaction index- WSI)}

$\mathrm{Bu}$ çalışmada, FAO tarafından istatistik ve bitki modelleme yaklaşımlarını kullanarak hava koşullarının bitki üzerindeki etkisini değerlendirmek için kullanılan, farklı araçların bir araya getirildiği AgroMetShell (AMS) modeli kullanılmıştır. AMS, ürünün toprak su bütçesini hesaplamak için kullanılan bitki, toprak ve meteorolojik verilerin üzerine inşa edilmiştir ve bazı tarımsal meteorolojik değişkenleri üretmektedir (FAO 2004). Yazılım veri analizi ve görüntü veri analizi (Image Data AnalysisIDA) fonksiyonlarını birleştirir. AMS modeli ile; 1)Veri tabanı fonksiyonları (yapılandırma, girdi, çıktı, veri yönetimi), 2) Ürünlerin izlenmesi ve risk analizleri yapılması için toplam 10 günlük bitkiye özel toprak su bütçesi ölçümleri, 3) Zirai meteorolojik değişkenler ve diğer göstergeler ile bunların grid formattaki çıktılarının uzaysal enterpolasyonu, 4) Gıda güvenliği bilgisi ve erken uyarı sisteminin kurulması ve çalıştırılması (FSIEWS-Food Security Information and Early Warning System), sağlanmaktadır.

FAO'nun Zirai Meteoroloji Birimi, 1974'ten başlayarak, FAO'nun Küresel Bilgi ve Erken Uyarı Sistemi içinde yer alan sahra altı ülkelerinde, bitki koşulları hakkında sürekli güncellenen bilgi ile desteklenen bir ürün tahmin metodolojisi kurmuş olup sürekli olarak geliştirmektedir. İlk zamanlarda, bitki özel su bütçesi tarafindan üretilen Su Yeterlilik İndeksi (Water Requirement Satisfaction IndexWRSI or WSI) ve bitki durumu arasındaki ilişkiyle ilgili niteliksel bir yöntem geliştirilmiştir (Frére \& Popov 1979; 1986; Gommes 1997; Gommes et al 1996). Bugün bu yöntem, hasat gerçekleşmeden birkaç ay önce ürün-verim miktarlarını tahmin etmede kullanılmaktadır.

Modelleme, büyüme sezonunun sürekli gözlenmesi esasına dayanır. Ekimden hasada kadar olan sürede, 10 günlük periyotta kümülatif olarak su bütçesi belirlenir. Yaklaşım, her 10 gün için, yağışın miktarını, dağılımını, bitki su ihtiyacını ve yağış verilerinden türetilen elverişli su miktarını hesaba katar. Bu durum, çeşitli zirai meteorolojik parametrelerin başlangıçta araştırılıp toplanmasını gerekli kılar. Bitki çeşidi, farklı büyüme safhalarının uzunluğu, toprak su tutma kapasitesi, etkili yağış ve yüzey akışı bunlardan bazılarıdır. Model, dinamik (su dengesi) ve istatistiksel (verim fonksiyonunun kalibrasyonu) yaklaşımlarının bir kombinasyonu olarak kabul edilir. Hasat zamanında, bitki tarafından yaşanan su stresinin 10'ar günlük toplamı WSI, bitki su tüketimi (gerçek evapotranspirasyon) ve diğer ilgili değişkenler verim tahmini için bir regresyon eşitliğinde birleştirilmiştir. Bütün model Bitkiye Özel Toprak Su Dengesi (Crop Specific Soil Water Balance-CSSWB) üzerine oturmaktadır.

WSI büyüme sezonu boyunca, ürünün su ihtiyacının karşılanıp karşılanmadığını açık olarak ifade eden bir göstergedir. FAO tarafından yapılan çalışmalar, belirli bir bitki için doğrusal verim azalma fonksiyonu kullanılarak WSI'nın bitki verimi ile ilişkilendirilmesinin mümkün olduğunu göstermiştir (Doorenbos \& Pruitt 1977; Frére \& Popov 1979; 1986). Bitki büyüme sezonunun sonunda veya sezondaki belirli bir on günlük dönemin sonunda, gerçek evapotranspirasyon (AETc) ve potansiyel evapotranspirasyonun (PETc) ayr1 ayr1 toplamının oranı, WSI'ın hesabında kullanılır. "Su açığı yok" durumunda WSI değeri 100 'dür ve bu su eksikliği ile ilgili bir verim azalmasının mevcut olmadığını ifade eder. WSI değerinin 50'nin altında olması durumunda bitki üretiminde bir başarısızlık olduğu değerlendirmesi yapılır (Smith 1992). Ürün verim tahminlerine temel teşkil eden WSI, gıda güvenliği için hazırlık ve planlama yapmaya katkı sağlar. Büyüme sezonu boyunca her on günlük dönemin sonunda bitki performansının bir göstergesi ve izleme aracı olarak değerlendirilir. Bir erken uyarı aracı olarak, uzun yıllar ortalama meteorolojik değerler kullanılarak bitkinin sezon sonu performansı tahmin edilebilir.

$$
W R S I=\frac{\sum A E T_{C}}{\sum P E T_{C}} \times 100
$$

$\mathrm{Bu}$ çalışmada AMS 1.51 model versiyonu kullanılmıştır. Şekil 2'de modelin ana kullanım yüzü görülmektedir. 
AMS modeli, 10'ar günlük su bütçesi yöntemi ile her bir istasyon için WSI indeks değerleri üretilmek üzere çalıştırılmıştır. Her istasyon için, uzun yıllar ortalama değerleri modele uygulanarak buğday için uzun yıllar ortalama WSI değerleri elde edilmiştir. Ankara ili uzun yıllar ortalama değerleri kullanılarak üretilen WSI grafiği Şekil 3’te verilmiştir.

Grafikte mavi sütunlar yağış miktarını, yeşil sütunlar ise gerçek evapotranspirasyon miktarını göstermektedir. Mart ayının son 10 gününden itibaren yağıştan oluşan nem miktarı gerçek evapotranspirasyonu karşılayamaz duruma gelmiştir. Mayıs ayının son 10 gününden itibaren de toprakta bitki için yetecek miktarda nem kalmamıştır. Üstteki kırmızı çizgi WSI değerini göstermekte olup, bu tarihten itibaren düşmeye başlamıştır. Daha sonraki dönemde yağış ve toprak nemi iyice azalmış ve WSI eğrisi hızla düşmüştür. $\mathrm{Bu}$ düşüş, üründe meydana gelen verim azalmasına işaret etmektedir. Çalışmada ayrıca 14 ayrı iklim değişikliği senaryosu için meteorolojik veriler oluşturularak modele girilmiş ve 14 ayrı senaryo için WSI değerleri elde edilmiştir.

Modelin üretmiş olduğu WSI indeksinin değerlendirilmesinde FAO tarafindan 6 adet sinıf oluşturulmuştur. Her bir sınıfa ait değerler Çizelge 1 'de verilmiştir. Ortalama ve üzerinde olan değerler, çalışılan bölgede verim yönünden az risk olduğunu, vasat ve altındaki değerler ise çok risk olduğunu göstermektedir.

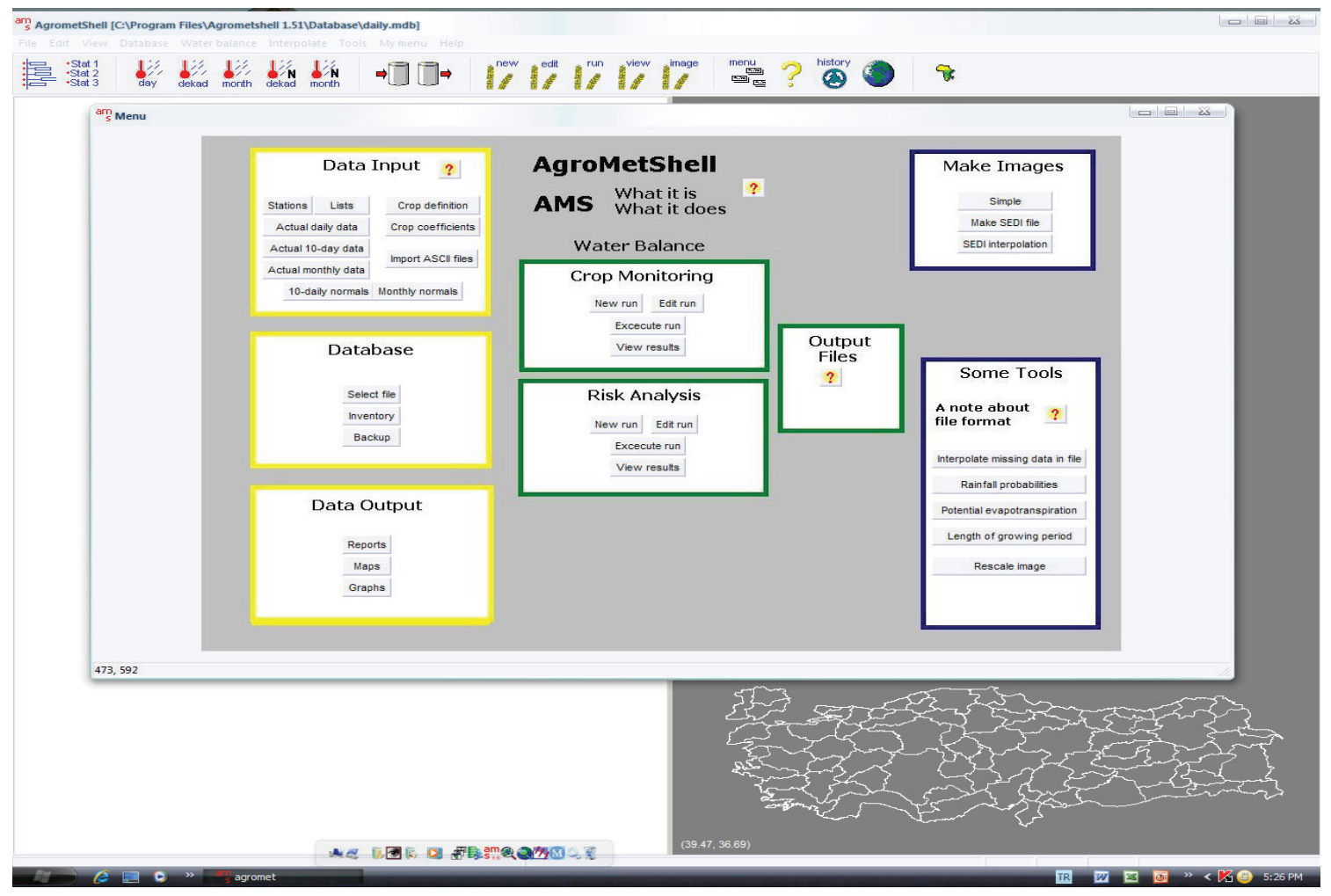

Şekil 2- AgroMetShell 1.51 modelinin ana kullanım yüzü

Figure 2- The modules for the Agrometshell 1.51 Model 


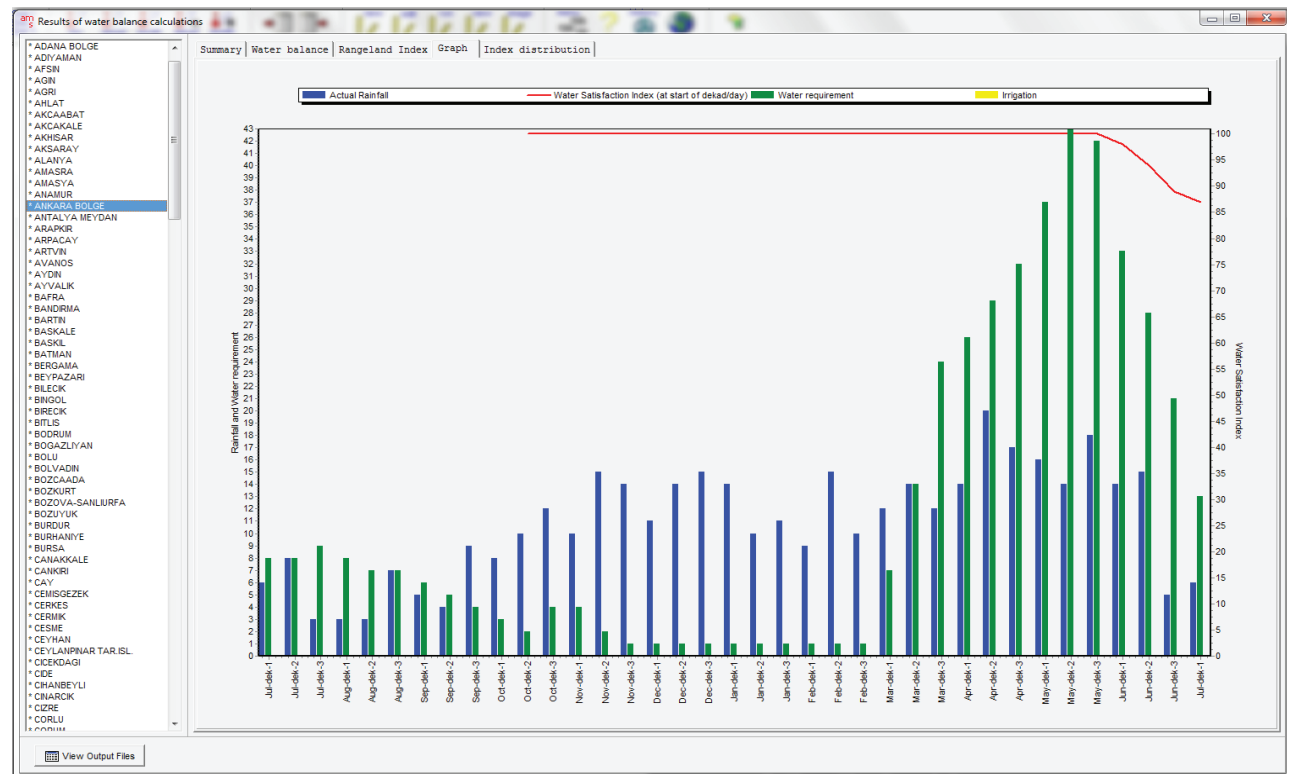

Şekil 3- Ankara istasyonunda buğdayın tarım yılı WSI grafiği

Figure 3- WSI agricultural year graphic of the wheat in Ankara

\section{Çizelge 1- WSI indeksi değerlendirme tablosu}

Table 1-Evaluation table of WSI index

\begin{tabular}{ccccccc}
\hline Değerlendirme & Çok iyi & İyi & Ortalama & Vasat & Kötü & Çok kötü \\
\hline WSI Limitleri & 100 & $99-95$ & $94-80$ & $79-60$ & $59-50$ & 50 'den az \\
\hline
\end{tabular}

\section{Bulgular ve Tartışma}

Bu çalışmada, her istasyon için, uzun yıllar ortalama değerleri kullanılarak AMS modeli çalıştırılmış ve buğday için uzun yıllar ortalama WSI değerleri elde edilmiştir. Ayrıca 14 ayrı iklim değişikliği senaryosu için meteorolojik veriler oluşturularak modele girilmiş ve WSI değerleri elde edilmiştir. WSI değerleri kullanılarak geleceğe dönük buğday veriminde meydana gelmesi muhtemel düşüşler incelenmiştir.

\subsection{Geleceğe dönük senaryolar ve hassasiyet analizi}

Dünyada nüfus artışına bağlı olarak su ve gıda ihtiyacı hızla artmaktadır. İklim değişikliği ve küresel ısınmanın etkileri ilgili hazırlanan raporlarda 21. yüzyılın ortaları ve sonunda sıcaklıkların önemli düzeylerde artacağı ve yağışların da azalacağı belirtilmektedir. Akdeniz Havzası'nda ve yarı kurak iklim kuşağında yer alan Türkiye için yapılan tahminlerde, özellikle güney ve batı bölgelerde sıcaklık artışı ve yağış azalması beklenmektedir.

Türkiye' de buğday üretiminin önemli bir kısmının gerçekleştiği 10 ilde oluşacak iklim değişiminin, temel gida maddesi olan buğday üretimini nasıl etkileyeceği gıda güvenliği açısından büyük önem arz etmektedir. Bu çalışmada AMS modeli kullanılarak olası sıcaklık, güneşlenme şiddeti artışları ve yağış azalışlarının ülkemizde buğday üretimi üzerinde meydana getireceği değişimler analiz edilmiştir. Sıcaklık, güneşlenme ve yağış parametrelerinde meydana gelmesi muhtemel tekli, ikili ve üçlü değişimler ayrı ayrı analiz edilerek buğday üretiminde oluşabilecek değişimler değerlendirilmiştir. 
Çalışmada göz önüne alınan senaryolarda, iklim değişikliği raporlarında ülkemiz için tahmin edilen değişimler analiz edilmiştir. Sicaklıklarda 1 ve $2{ }^{\circ} \mathrm{C}^{\prime} l i k$ artışlar, güneşlenme şiddetinde $\% 10$ ve 20 'lik artışlar, yağışta \% 10 ve 20 'lik azalışlar tekli, ikili ve üçlü olarak modele girilerek muhtemel verim değişiklikleri tespit edilmiştir. Yapılan 14 farklı senaryoda 10 ilde buğday için elde edilen WSI değerleri ve normal yıl için elde edilen WSI değerlerinin karşılaştırması yapılmıştır. Çalışmaya konu olan tüm senaryolar Çizelge 2'de verilmiştir.

Yapılan tüm analizlerde verimde azalmalar olabileceği belirlenmiştir. En az azalma sıcaklığın $1^{\circ} \mathrm{C}^{\prime}$ lik artışı sonucunda $\% 1.8$, en fazla ise sıcaklığın $2^{\circ} \mathrm{C}^{\prime}$ lik, güneşlenme şiddetinin \% 20'lik artışı ve yağışın \% 20'lik azalması sonucunda $\% 18.2$ olarak gerçekleşmektedir. Hassasiyet analizi sonuçları Çizelge 3 'de verilmiştir.

Sıcaklık, güneşlenme şiddeti ve yağış tek tek değerlendirildiğinde en fazla düşüş $\% 6.5$ ile yağışın \% 20'lik azalması durumunda ortaya çıkmaktadır. İkili değerlendirmelerde en fazla düşüş \% 13.2'lik azalma ile güneşlenme şiddetinin $\%$ 20'lik artış1, yağışın \% 20'lik azalması durumunda meydana gelmektedir. Üçlü analizlerde ise en fazla düşüş $\%$ 18.2'lik azalma ile sıcaklığın $2^{\circ} \mathrm{C}^{\prime}$ lik, güneşlenme şiddetinin \% 20'lik artışı ve yağışın \% 20'lik azalışı durumunda oluşmaktadır. Hassasiyet analizi sonuçlarına ilişkin grafik Şekil 4'de verilmiştir.

Çizelge 2- Analiz edilen iklim değişikliği senaryoları

Table 2-Scenarios of analyzed climate change

\begin{tabular}{cc}
\hline Senaryo no & Senaryo adı \\
\hline 1 & Sic +1 \\
2 & Sic +2 \\
3 & Gün $+\% 10$ \\
4 & Gün $+\% 20$ \\
5 & Yağ $-\% 10$ \\
6 & Yağ $-\% 20$ \\
7 & Sic +1 ve Gün $+\% 10$ \\
8 & Sic +2 ve Gün $+\% 20$ \\
9 & Sic +1 ve Yağ $-\% 10$ \\
10 & Sic +2 ve Yağ $-\% 20$ \\
11 & Gün $+\% 10$ ve Yağ $-\% 10$ \\
12 & Gün $+\% 20$ ve Yağ $-\% 20$ \\
13 & Sic +1 ve Gün $+\% 10$ ve Yağ $-\% 10$ \\
14 & Sic +2 ve Gün $+\% 20$ ve Yağ $-\% 20$ \\
\hline
\end{tabular}

\section{Çizelge 3- Hassasiyet analizi sonuçları}

Table 3- The results of sensivity analysis

\begin{tabular}{|c|c|c|c|c|c|c|c|c|c|c|c|}
\hline ISTASYON & 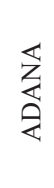 & $\begin{array}{l}\text { 㐫 } \\
\text { 学 }\end{array}$ & 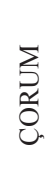 & 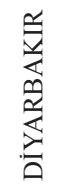 & 岩 & $\underset{\Downarrow}{\overleftarrow{Z}}$ & $\begin{array}{l}\mathbb{1} \\
\text { 号 } \\
\text { 号 } \\
\text { 芯 }\end{array}$ & $\sum_{\infty}^{\infty}$ & 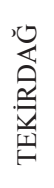 & 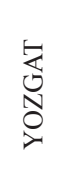 & 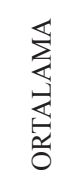 \\
\hline $\mathrm{S}+1 \mathrm{WSI}$ & 0 & -4 & -3 & -3 & 0 & 0 & -3 & -3 & 0 & -2 & -1.8 \\
\hline S+2 WSI & 0 & -8 & -6 & -5 & 0 & -3 & -7 & -6 & 0 & -5 & -4 \\
\hline GŞ+\%10 WSI & 0 & -6 & -5 & -3 & 0 & -2 & -4 & -5 & 0 & -3 & -2.8 \\
\hline GŞ+\%20 WSI & 0 & -10 & -9 & -7 & 0 & -4 & -9 & -10 & 0 & -8 & -5.7 \\
\hline Y-\%10 WSI & 0 & -4 & -4 & -3 & 0 & -5 & -4 & -4 & 0 & -4 & -2.8 \\
\hline Y-\%20 WSI & 0 & -12 & -8 & -7 & 0 & -12 & -9 & -8 & 0 & -9 & -6.5 \\
\hline $\mathrm{S}+1$ ve $\mathrm{GSS}+\% 10 \mathrm{WSI}$ & 0 & -9 & -8 & -6 & 0 & -6 & -8 & -8 & 0 & -7 & -5.2 \\
\hline $\mathrm{S}+2$ ve GŞ +\%20 WSI & -5 & -16 & -14 & -12 & -2 & -9 & -15 & -14 & 0 & -15 & -10.2 \\
\hline S+1 ve Y-\%10 WSI & 0 & -8 & -6 & -6 & 0 & -7 & -7 & -7 & 0 & -8 & -4.9 \\
\hline $\mathrm{S}+2$ ve $\mathrm{Y}-\% 20 \mathrm{WSI}$ & -4 & -19 & -13 & -12 & -4 & -16 & -14 & -13 & 0 & -16 & -11.1 \\
\hline GŞ +\%10 ve Y-\%10 WSI & 0 & -11 & -8 & -6 & 0 & -10 & -8 & -9 & 0 & -8 & -6 \\
\hline GŞ +\%20 ve Y-\%20 WSI & -7 & -21 & -16 & -14 & -5 & -17 & -17 & -17 & 0 & -18 & -13.2 \\
\hline S+1 ve GŞ +\%10 ve Y-\%10 WSI & -2 & -14 & -11 & -10 & 0 & -12 & -12 & -11 & 0 & -12 & -8.4 \\
\hline $\mathrm{S}+2$ ve GŞ +\%20 ve Y-\%20 WSI & -13 & -27 & -20 & -18 & -12 & -20 & -22 & -21 & -5 & -24 & -18.2 \\
\hline
\end{tabular}




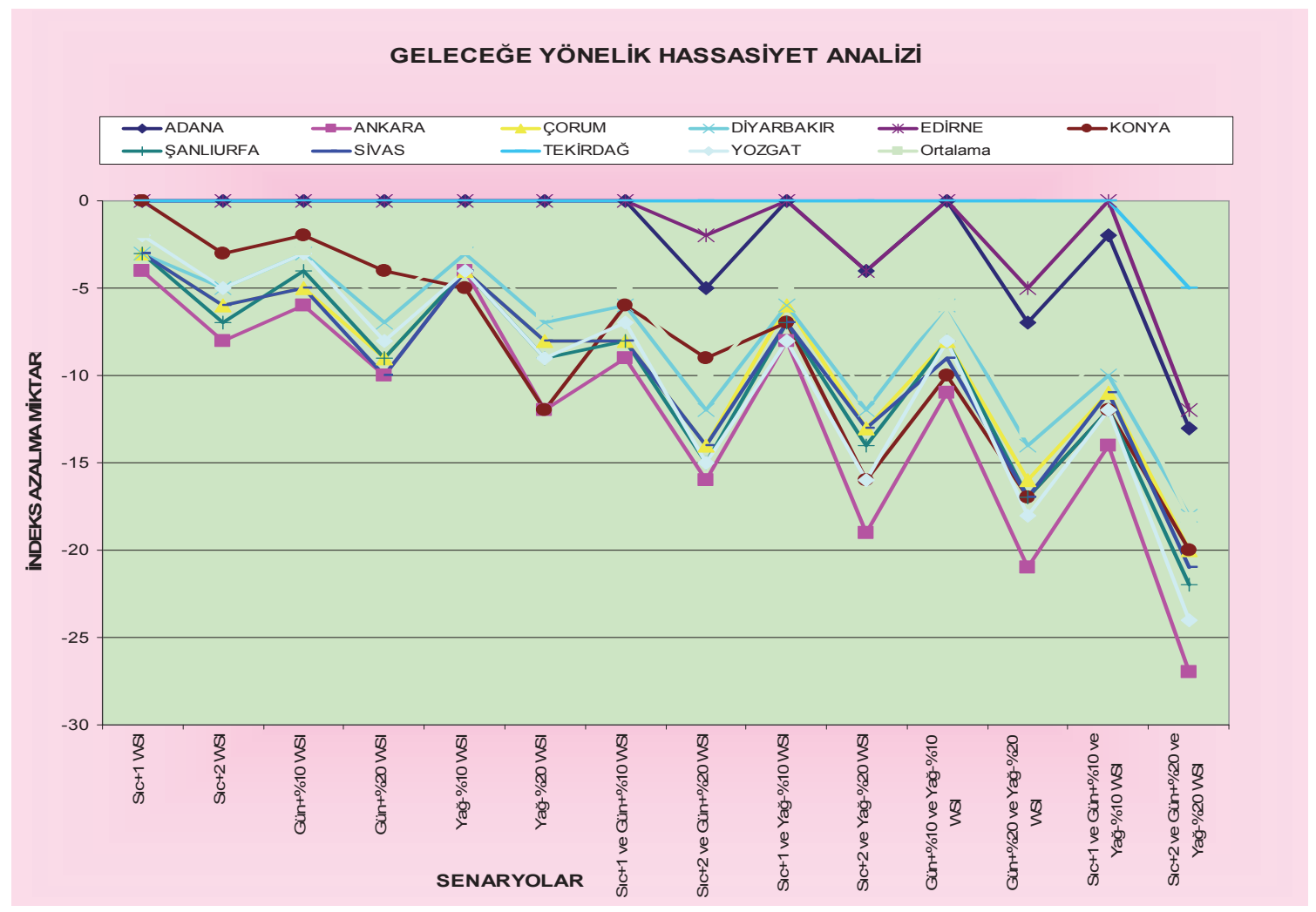

\section{Şekil 4- Hassasiyet analizi sonuçları grafiği}

Figure 4- Graphic of sensivity analysis results

Senaryolarda özellikle sıcaklık ve güneşlenme şiddeti artışı durumlarında bitki gelişiminin baharda daha erken başlaması, vejetasyon süresinin daha erken ve daha kısa sürede tamamlanması söz konusu olabilecektir. $\mathrm{Bu}$ durumda bitki beklenenden daha az strese gireceğinden verim düşüşünün beklenen değerlerden daha az olacağ 1 söylenebilir. Bunun yanında göz önünde bulundurulması gereken bir diğer durum ise beklenen değişimlerin her bölgede aynı derecede olmayacağı gerçeğidir. Türkiye'nin her bölgesinde aynı derecede sıcaklık ve güneşlenme şiddeti artışı olması ve yağışın düşmesi beklenmemektedir. Olumsuz etkilerin güney ve batı bölgelerde yüksek oranda hissedileceği, kuzey ve doğu kesimlerde ise daha az görüleceği bildirilmektedir. Bu çalışmada, 10 ilde de aynı derecede olumsuz etki dikkate alınmış olduğundan en kötü durumu ifade etmektedir ve olabilecek maksimum verim azalışını göstermektedir. Bazı illerin bu değişimden daha az etkileneceği düşünülürse beklenen toplam verim azalışı daha az olacaktır.

FAO tarafından geliştirilen ürün izleme, verim tahmin sistemi ve bunun beyni olan AMS gelişmekte olan birçok ülke tarafından kullanılmaktadır. Değişik projeler vasıtasıyla bu sistemle ilgili eğitimler yapılmış ve çok sayıda ülkede bu modelin ve sistemin kullanılması sağlanmıştır. Bu kapsamda Türkiye, Afganistan, Azerbaycan, Gürcistan, Kırgızistan, Pakistan, Ermenistan, Mozambik, Arjantin, Bangladeş, Kenya, Doğu Afrika ve Güney Afrika gibi ülkeler sayılabilir (FAO 2011).

Kenya'da mısır bitkisi için AMS kullanılarak ürün izleme ve verim tahmini çalışmaları yapılmıştır 
(Rojas 2007). AMS tarafından üretilen parametreler (WSI; ETA) ve SPOT uydusundan alınan NDVI değerleri kullanılarak mısır üretimi tahmin edilmeye çalışılmıştır. CNDVI ve ETA değerleri mısır verim değişiminin \%83'ünü tarif etmektedir. Modelin tahmin tutarlılığ $\left(\mathrm{R}^{2}\right)=0.81$ ve ortalama hata 0.359 $\mathrm{t} / \mathrm{h}$ olarak belirlenmiştir.

Türkiye'de de FAO ile yürütülen Teknik İşbirliği Projesi kapsamında AMS modeli kullanılarak verim tahminleri yapılmıştır. AMS modelinin çalıştırılabilmesi için gerekli olan meteorolojik veriler, bitki katsayıları, fenolojik gözlemler, toprak özellikleri ve NDVI görüntüleri hazırlanmıştır. Sulama yapılmadığı kabul edilerek, 265 istasyon için model çalıştırılmıştır. İstasyon bazında WSI değerleri elde edilmiştir. NDVI görüntüleri yardımıyla WSI değerleri araziye yayılmış ve il bazında ortalama değerler elde edilmiştir. Bulunan indeks değerleri ile TÜİK'e ait, illerin ortalama verim değerleri arasında istatistiksel analizler yapılmıştır. Sonuçta 2005 ve 2006 yılları için il bazında verim tahminleri elde edilmiştir. TÜíK'ten alınan istatistik verim değerleri ve modelin 2005, 2006 verim tahmini değerleri kullanılarak haritalar oluşturulmuştur. Tahmin edilen verim değerleri ile geçekleşen değerler arasında $\mathrm{R}^{2}=0.9067$ düzeyinde bir ilişki tespit edilmiştir (Şimşek et al 2007).

Türkiye'de bu konuda yapılan önemli çalışmalardan birisi de meteorolojik faktörlerin bitki gelişimine etkilerinin belirlenmesinde bitkiiklim modellerinin kullanılmasının araştırıldığ tez çalışmasıdır (Çaldağ 2000). İki farklı ölçüm döneminde Kırklareli'nde yapılan bu çalışmada; buğday bitkisinin sıcaklık, radyasyon, yağış ve $\mathrm{CO}_{2}$ değişimlerinden nasıl etkilendiği araştırılmıştır. Bu amaçla DSSATv3.5 yapısı içinde buğday için geliştirilen CERES-Wheat Modeli ile SIMWASER Modeli kullanılmıştır.

AMS modeli evapotranspirasyon hesabında dünyada yaygın olarak kullanılan modifiye FAO Penman-Monteith yöntemini (Allen et al 1998) kullanmakta olup bu durum su bütçesi ve WSI hesabının iyi sonuçlar vermesini sağlamıştır. Çaldağ (2000) tarafından yapılan araştırmada yağışın ihtiyaçtan fazla olması ve sıcaklığın düşük kalması nedeniyle, elde edilen değerler kurak ve sıcak bölgelerde ortaya çıkan sonuçlardan farklılık göstermiştir. Çalışmada sıcaklık ve radyasyon miktarının artması evapotranspirasyonu artırmakta, sonuçta su bütçesi daha fazla açık vermekte, WSI değerleri ve verim düşmektedir. Yağış azaltıldığında ise su açığı artmakta, WSI değerleri ve verim düşmektedir.

İklim değişikliği senaryolarını esas alarak, AMS modeli ile geleceğe dönük olarak verim tahmini çalışması Dünya Bankası tarafından finanse edilen bir projede yapılmıştır (FAO 2008). Rene Gommes başkanlığındaki bir ekip tarafından tamamlanan "FAS'ta Tarım Sektörü Üzerine İklim Değişikliğinin Etkileri” isimli proje ile gelecek yıllar için üretilen iklim değişikliği senaryoları AMS modeline girilerek geleceğe dönük verim tahminleri yapılmıştır. Çalışma 5 aşamada gerçekleştirilmiştir: 1) Fas için geleceğe dönük iklim projeksiyonları, 2) Tarımsal verim üzerine etkisi, 3) Su kaynakları üzerine etkisi, 4) Ekonomik etkisi, 5) İklim değişikliğine adaptasyon için kamu politikası seçenekleri. HadCM3 modeli ile elde edilen A2 ve B2 senaryoları kullanılarak elde edilen tahminlerden 2000, 2030, 2050 ve 2080 dönemlerinde, sulanan ve sulanmayan 50 bitki için 6 agroekolojik zon bölgesinde çalışılmıştır.

\section{Sonuçlar}

$\mathrm{Bu}$ çalışmada, iklim değişikliğinin Türkiye'de buğday verimine etkileri farklı iklim senaryoları için AMS modeli kullanılarak analiz edilmiştir. WSI indeksi, değişik ürünler ve değişik bölgeler için hesaplanarak büyüme periyodu boyunca tarımsal kuraklıktan etkilenme durumu sürekli olarak takip edilebilir. İklim değişikliği modellerinden alınacak çıktılar kullanılarak, geleceğe yönelik olarak, istenilen noktada, istenilen ürün için oluşabilecek zarar ve verim düşüşü tahmin edilebilir. AMS ve ürettiği WSI üreticiler, araştırmacılar ve karar vericiler için çok yönlü faydalı olabilecek bir araçtır.

$\mathrm{Bu}$ çalışmada karşılaşılan en önemli sorun, Türkiye'de model kullanımı için gerekli olan 
verilerin çok yetersiz olmasıdır. Yeterli olmamakla birlikte en kolay ulaşılan ve sayısal ortamda hazır bir şekilde tutulan veri, meteorolojik veridir. Toprak verileri ise genellikle bulunamamaktadır. Yeterli ve güvenilir fenolojik veri yoktur. Bitki katsayıları ile ilgili yeterli çalışma bulunmamaktadır. Bulunamayan veriler için uluslararası kurumların verileri ve model tarafından önerilen değerler kullanılmıştır. Türkiye için daha doğru sonuçlara ulaşılabilmesi için model çalışmalarında gerekli olan veri tabanlarının en kısa sürede oluşturulması gerekmektedir. Modellerin kalibrasyonu için de tüm parametrelerin yerinde ölçüm ve karşılaştırmalarının yapılması gerekmektedir.

\section{Kaynaklar}

Allen G R, Pereira L S, Raes D \& Smith M (1998). Crop Evapotranspiration. FAO Irrigation and Drainage Paper, No 56, Rome, Italy

Çaldağ B (2000). Meteorolojik faktörlerin bitki gelişimine etkilerinin bitki-iklim modelleri ile belirlenmesi. Yüksek Lisans Tezi, İstanbul Teknik Üniversitesi, Fen Bilimleri Enstitüsü (Basılmamıș), İstanbul

ÇOB (2007). İklim Değişikliği Birinci Ulusal Bildirimi. Çevre ve Orman Bakanlığı, Çevre Yönetimi Genel Müdürlüğü, Ankara, Türkiye

DMİ (2011). Meteorolojik Gözlemler. DMİ Genel Müdürlüğü İstatistik ve Yayın Şube Müdürlüğü, Ankara, Türkiye

Doorenbos J \& Pruitt W O (1977). Crop Water Requirements. FAO Irrigation and Drainage Paper No. 24, Rome, Italy

FAO (2004). AgroMetShell Toolbox CD-ROM. FAOSDRN Working Paper Series. Rome, Italy: FAO - 124

FAO(2008).http://www.fao.org/nr/climpag/pub/FAO_ WorldBank_Study_CC_Morocco_2008.pdf.

FAO (2011). Available: http://www.hoefsloot.com/ agrometshell.htm

Frère M \& Popov G F (1979). Agrometeorological Crop Monitoring and Forecasting. FAO Plant Production and Protection, Paper No. 17. Rome, Italy
Frère M \& Popov G F (1986). Early Agrometeorological Crop Yield Forecasting. FAO, Plant Production and Protection Paper No. 73. Rome, Italy

Gommes R (1997). FAO's Experience in the Provision of Agrometeorological Information to the User Community. Workshop on User Requirements for Agrometeorological Services, November 10-14, 1997, Pune, India

Gommes R, Snijders F L \& Rijks J Q (1996). The FAO Crop Forecasting Philosophy in National Food Security Warning Systems. Chapter 6 in Report of the EU Support Group on Agrometeorology. EU-JRC official pub. of the EU paper series

Herdem Z, Doğan M, Yeşilyurt N, Akçı M, Çelenk H, Keskin S, Pasin V, Duman H, Egemen M, Doğan O, Tutar S, Kuzuoğlu E, Odabaşı A \& Koç M (2002). Buğday ve Arpa Tarımı. Tarım İşletmeleri Genel Müdürlüğü, Ankara

IPCC (2007). Climate Change 2007: The Physical Science Basis. Contribution of Working Group I to the Fourth Assessment Report of the Intergovermental Panel on Climate Change, Summary for Policy Makers, Paris

Mukhala E \& Hoefsloot P (2004). AgroMetShell Manual. Rome, Italy

Rojas O (2007). Operational maize yield model development and validation based on remote sensing and agro-meteorological data in Kenya. International Journal of Remote Sensing 28 (17): 3775-3793

Smith M (1992). Expert Consultation on Revision of FAO Methodologies for Crop Water Requirements. Publication 73, FAO, Rome

Şimşek O, Mermer A, Yıldız H, Özaydın K A \& Çakmak B (2007). AgroMetShell modeli kullanılarak Türkiye'de buğdayın verim tahmini. Ankara Üniversitesi Ziraat Fakültesi Tarım Bilimleri Dergisi 13 (3): 299-307

Şimşek O (2010). Türkiye'de tarım yılı kuraklık değerlendirmesi ve bitki gelişim modeli ile buğdayda kuraklık-verim analizi. Doktora Tezi, Ankara Üniversitesi, Fen Bilimleri Enstitüsü (Basılmamış), Ankara

Şimşek O \& Çakmak B (2010). Drought analysis for 2007-2008 agricultural year of Turkey. Tekirdag Ziraat Fakültesi Dergisi 7(3):99-109 